\title{
Evaluation of nasal morphology in predicting vertical and sagittal maxillary skeletal discrepancies'
}

\author{
Mandava Prasad ${ }^{1}$, Nellore Chaitanya ${ }^{1}$, Karnati Praveen Kumar Reddy ${ }^{1}$, Ashok Kumar \\ Talapaneni $^{1}$, Vijaya Bhaskar Myla ${ }^{1}$, Sharath Kumar Shetty ${ }^{2}$
}

Correspondence: Dr. Mandava Prasad

Email: mandavabruno9@hotmail.co.in

\begin{abstract}
'Department of Orthodontics and Dentofacial Orthopedics, Narayana Dental College and Hospital, Nellore, Andhra Pradesh, India,

2Department of Orthodontics, KVG Dental College, Sullia, Karnataka, India
\end{abstract}

\section{ABSTRACT}

Objective: The purpose of this prospective observational study was to evaluate the relationship between nasal morphology and maxillary skeletal pattern. The clinical significance was to emphasize the importance of role of nasal pattern in diagnosis and treatment planning. Materials and Methods: The sample included the pre-treatment lateral cephalometric radiographs of 180 South Indian adults (94 women, 86 men), aged 18 to 28 years. Six maxillary and six nasal soft tissue parameters were measured. Pearson correlation coefficients and Analysis of variance were used for statistical analyses. Results: There were significant correlations between maxillary vertical and sagittal, skeletal and soft tissue parameters. The Mean and standard deviations were correlated between low insignificant range to high significant levels with nasal length, nasal depth and columella convexity. Nasal length also showed significant correlation with inclination of palatal plane. Significant influence of gender was seen on nasal length, nasal depth, columella convexity and nasal tip angle. A statistically significant difference was seen regarding nasal length between males and females, with nasal length being more in males $(50.26 \pm 4.18)$ than in females $(48.86 \pm 3.45)$, nasal depth being more in males $(18.64 \pm 2.56)$ than in females $(16.63 \pm 2.16)$, columella convexity being greater in males $(4.31 \pm 1.26)$ than in females $(3.41 \pm 1.13)$, nasolabial angle decreased in males $\left(87.26^{\circ} \pm 13.79^{\circ}\right)$ than in females $\left(89.38^{\circ} \pm 15.72^{\circ}\right)$ and nasal tip angle being more in females $\left(80.18^{\circ} \pm 9.44^{\circ}\right)$ than in males $\left(73.60^{\circ} \pm 10.24^{\circ}\right)$. There was no statistically significant difference in nasal hump between males $(-2.01 \pm 1.76)$ and females $(-2.02 \pm 1.62)$. Conclusion: Long nose with increased nasal prominence were seen with increase in the anteroposterior length and vertical height of maxilla. Male and female genders had a varied amount of nasal length, nasal depth and columella convexity along with nasal tip angle.

Key words: Nasal hump, nasal length, sagittal and vertical maxillary deficiency, sagittal and vertical maxillary excess

\section{INTRODUCTION}

Beauty is the finest expression of human emotions. The improvement of facial esthetics has rapidly become one of the desirable objectives of orthodontic treatment. ${ }^{[1]}$ The role of the hard skeletal structure in influencing the facial form is a recognized and accepted fact. ${ }^{[2]}$ Superimposed upon a dento-skeletal framework lies a variable soft tissue mass comprising epithelium, connective tissue, and muscle. Variation in this soft tissue veneer can be an important factor in case analysis. ${ }^{[3]}$ Less attention has been directed towards providing information, which could aid the clinician in producing a well-proportioned, balanced, and harmonious soft tissue profile at the end of the treatment. ${ }^{[4]}$

Facial harmony in orthodontics is determined by the morphologic relationships and proportions of the nose, lips, and chin. ${ }^{[5]}$ As the nose is located in the center of the face, it serves together with the lips and the chin to characterize the facial appearance, which is unique to every individual. ${ }^{\left[{ }^{[6]}\right.}$ Together with its respiratory function, the configuration of the nose also has a strong impact on overall facial

\footnotetext{
How to cite this article: Prasad M, Chaitanya N, Reddy KK, Talapaneni AK, Myla VB, Shetty SK. Evaluation of nasal morphology in predicting vertical and sagittal maxillary skeletal discrepancies'. Eur J Dent 2014;8:197-204.

Copyright @ 2014 Dental Investigations Society. DOI: $10.4103 / 1305-7456.130600$
} 
esthetics $^{[7]}$ and greatly influences the degree of profile convexity. ${ }^{[8]}$

Nasal growth proceeds at a relatively constant rate into adolescence and is almost completed by the age of 16 years in girls and 18 years in boys. However, long-term studies by Behrent indicated a considerable amount of nasal growth during adulthood. ${ }^{[6]}$ Previous studies on nose growth (Subtelny, Posen, Chaconas, Wisth) agree that the growth is in a downward and anterior direction, with a yearly increase in nose length of approximately 1.5 millimeters. ${ }^{[8]}$

The form and profile of the nose depends upon both the bony and cartilaginous components and upon the overlying muscles and the integument. All of the elements vary in size, in shape, and in their spatial relation to one another. ${ }^{[9]}$ The cartilaginous nasal septum has been shown, in animal experiments, to play an important role in the development not only of the nose but also of the maxilla. ${ }^{[10]}$ Scott suggested that the cartilaginous nasal septum is a primary growth center, which pushes and thrusts the mid face downwards and forward, and also no morphologic or chronologic differences in development of the cranial base were detected between the normal and cleft fetuses. ${ }^{[11]}$

The goal of orthodontic treatment targets improvement of patients life through enhancement of dentofacial functions and esthetics, to reduce orthodontic treatment duration is an issue of importance, particularly for adults, ${ }^{[12]}$ Changes in the soft-tissue profile with age follow the growth in the underlying hard tissues but are not directly correlated. The convexity of the face increases with age, as nasal growth mainly occurs in the antero-inferior direction. ${ }^{[13]}$ Although orthodontic treatment does not affect the shape of the nose, the proximity of the nose to tissues affected by such treatment suggests that more long-term consideration should be given to nasal growth and development. ${ }^{[14]}$

The present study was aimed to correlate nasal morphology with sagittal and vertical maxillary skeletal pattern and to evaluate the influence of gender on nasal pattern.

\section{MATERIALS AND METHODS}

A random sample consisting the pre-treatment lateral cephalograms of 180 South Indian adults (94 women,
86 men) with mean ages between 18 and 28 years were selected from the records of the Orthodontics department, Narayana Dental College and Hospital between 2006 and 2012. All the individuals were in the permanent dentition, and none had any facial congenital anomaly or prior history of orthodontic treatment, surgery, or trauma to the face. Six maxillary skeletal and nasal soft tissue parameters ${ }^{[15,16]}$ were identified on the standard lateral cephalograms, and were recorded on a lead acetate tracing paper with a $3 \mathrm{H}$ pencil. To test the reliability of measurements used (error of method evaluation), 50 cephalometric radiographs were selected at random and were retraced in an interval of 1 week. Method errors were calculated by Dahlberg's formula. Thereafter, the measurements were compared by the paired $t$ test for evaluation of systematic errors, at a significance level of $5 \%(P<0.05)$.

Various cephalometric landmarks, reference planes were used to assess the maxillary skeleton and the nose [Figures 1 and 2].

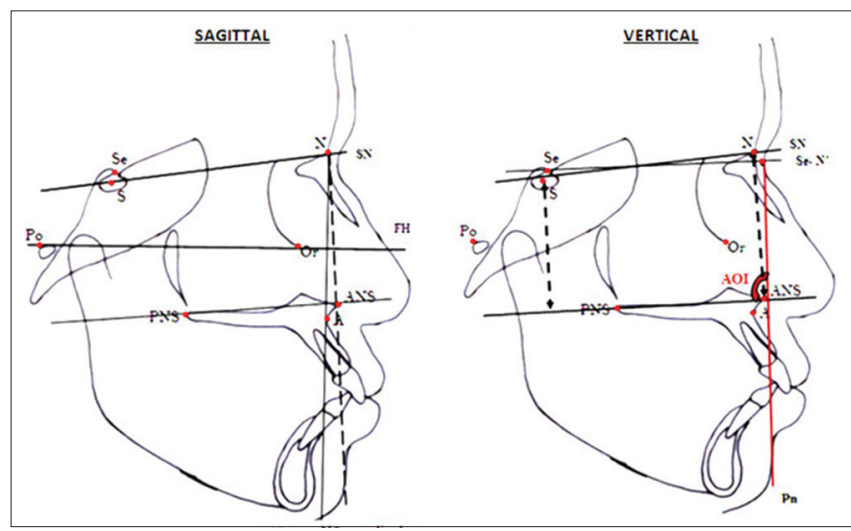

Figure 1: Maxilla - soft tissue and hard tissue landmarks and planes

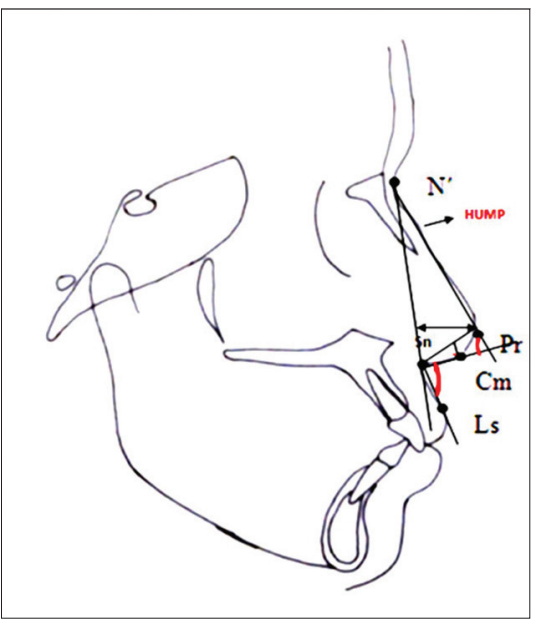

Figure 2: Nose -soft tissue and hard tissue landmarks and planes 


\section{Statistical analysis}

The statistical analysis of the observations included descriptive and inferential statistics. Normality assumptions of data distribution were tested by Shapiro-wilks test. Data was summarized by means and standard deviation. Pearson correlation coefficient test was used to determine whether soft tissue nasal parameters had a linear correlation with maxillary skeletal measurements and also to determine the extent of correlation within nasal parameters. The one-way analysis of variance (ANOVA) was used to analyze the effect of gender variations on nasal parameters. The statistical analyses were performed with SPSS software (version 20).

\section{Error analysis}

To test the reliability of measures used (error of method evaluation), 50 cephalometric radiographs were selected at random and were retraced in an interval of 1 week. Method errors were calculated by Dahlberg's formula. Thereafter, the measurements were compared by the paired $t$ test for evaluation of systematic errors, at a significance level of 5\% $(P<0.05)$.

\section{RESULTS}

The descriptive data of maxillary skeletal and soft tissue nasal parameters [Table 1] were correlated with Pearson correlation coefficients between the maxillary skeletal and soft tissue nasal parameters [Table 2].

- Nasal length showed statistically insignificant very low positive correlation with SNA $(P=0.26$, $r=0.084)$, very low positive correlation with $\mathrm{N}$ perpendicular to $\mathrm{A}(P=0.34, r=-0.071)$, PNS-A $(P=0.04, r=0.151)$. It showed very high statistically significant $(P<0.001)$, high positive correlation with upper anterior facial height (N-ANS, $r=0.723$ ), a very high statistically significant $(P<0.001)$ low positive correlation with upper posterior facial height (S-PNS, $r=0.299$ ), a very high statistical significant $(P<0.001)$, low negative correlation with angle of inclination (AOI, $r=-0.340)$.

- Nasal depth showed statistically insignificant $(P=0.89)$ very low negative correlation with SNA $(r=-0.10)$, a statistically insignificant $(P=0.84)$ very low positive correlation with $\mathrm{N}$ perpendicular to A $(r=-0.015)$, a very high statistically significant $(P<0.001)$ low positive correlation with length of maxillary base (PNS-A, $r=0.28$ ), a very high statistically significant $(P<0.001)$ low positive correlation with upper anterior facial height (N-ANS, $r=0.43$ ), a very high statistically

\begin{tabular}{|c|c|c|c|c|c|c|}
\hline & $\begin{array}{l}\text { N-LEN } \\
(\mathrm{mm})\end{array}$ & $\begin{array}{c}\text { N-DEP } \\
(\mathrm{mm})\end{array}$ & $\begin{array}{c}\text { NLA } \\
\left({ }^{\circ}\right)\end{array}$ & $\begin{array}{c}\text { N-Pr-Cm } \\
\left({ }^{\circ}\right)\end{array}$ & $\begin{array}{c}\text { Cconv } \\
(\mathrm{mm})\end{array}$ & $\begin{array}{l}\text { HUMP } \\
(\mathrm{mm})\end{array}$ \\
\hline \multirow[t]{2}{*}{ SNA } & 0.084 & -0.010 & -0.006 & -0.019 & 0.014 & 0.078 \\
\hline & 0.26 & 0.89 & 0.93 & 0.80 & 0.85 & 0.30 \\
\hline \multirow[t]{2}{*}{ N PER A } & 0.071 & 0.015 & 0.056 & -0.013 & 0.046 & -0.098 \\
\hline & 0.34 & 0.84 & 0.45 & 0.86 & 0.54 & 0.19 \\
\hline \multirow[t]{2}{*}{ PNS-A } & $0.151^{*}$ & $0.288^{\star *}$ & -0.102 & $-0.171^{*}$ & $0.280^{\star *}$ & 0.001 \\
\hline & 0.04 & 0.00 & 0.17 & 0.02 & 0.00 & 0.99 \\
\hline \multirow[t]{2}{*}{ N-ANS } & $0.723^{\star *}$ & $0.432^{* *}$ & 0.021 & -0.108 & $0.225^{\star *}$ & -0.086 \\
\hline & 0.00 & 0.00 & 0.78 & 0.15 & 0.00 & 0.25 \\
\hline \multirow[t]{2}{*}{ S-PNS } & $0.299^{* *}$ & $0.292^{* *}$ & 0.057 & -0.099 & $0.216^{\star *}$ & -0.037 \\
\hline & 0.00 & 0.00 & 0.45 & 0.19 & 0.00 & 0.62 \\
\hline \multirow[t]{2}{*}{$\mathrm{AOI}$} & $-0.340^{\star *}$ & -0.010 & -0.019 & -0.071 & 0.039 & 0.071 \\
\hline & 0.00 & 0.90 & 0.80 & 0.34 & 0.61 & 0.35 \\
\hline
\end{tabular}

SNA: Sella nasion angle, N-Pr-Cm: Nasal tip angle, AOI: Angle of inclination, N DEP: N Depth, NLA: N Length, Cconv: Columella convexity, HUMP: Nasal hump, N-Pr-Cm: Nasal tip angle

\begin{tabular}{lcccccccc}
\multicolumn{2}{l}{ Table 1: Descriptives of maxillary skeletal and nasal parameters } \\
\cline { 1 - 1 }
\end{tabular}


significant $(P<0.001)$ low positive correlation with upper posterior facial height (S-PNS, $r=0.292)$, a statistically insignificant $(P=0.90)$ very low negative correlation with angle of inclination (AOI, $r=-0.01)$.

- Nasolabial angle (NLA) showed statistically insignificant $(P=0.93)$ very low negative correlation with SNA $(r=-0.006)$, a statistically insignificant $(P=0.45)$ very low positive correlation with $\mathrm{N}$ perpendicular to $\mathrm{A}(r=0.056)$, a statistically insignificant $(P=0.17)$ very low negative correlation with length of maxillary base (PNS-A, $r=-0.012)$, a statistically insignificant $(P=0.78)$ very low positive correlation with upper anterior facial height (N-ANS, $r=0.021)$, a statistically insignificant $(P=0.45)$ very low positive correlation with upper posterior facial height (S-PNS, $r=0.57$ ), a statistically insignificant $(P=0.80)$ very low negative correlation with angle of inclination (AOI, $r=-0.019$ ).

- Nasal tip angle (N-Pr- $\mathrm{Cm}$ ) showed a statistically insignificant $(P=0.80)$ very low negative correlation with SNA $(r=-0.019)$, a statistically insignificant $(P=0.86)$ very low negative correlation with $\mathrm{N}$ perpendicular to $\mathrm{A}(r=-0.013)$, a statistically significant $(P=0.02)$ very low negative correlation with length of maxillary base (PNS-A, $r=-0.171)$, a statistically insignificant $(P=0.15)$ very low negative correlation with upper anterior facial height (N-ANS, $r=-0.108)$, a statistically insignificant $(P=0.19)$ very low negative correlation with upper posterior facial height (S-PNS, $r$ $=-0.099)$, a statistically insignificant $(P=0.34)$ very low negative correlation with angle of inclination (AOI, $r=-0.071$ ).

- Columella convexity showed a statistically insignificant $(P=0.85)$ very low positive correlation with SNA $(r=0.014)$, a statistically insignificant $(P=0.54)$ very low positive correlation with $\mathrm{N}$ perpendicular to A $(r=0.046)$, a very high statistically significant $(P<0.001)$ low positive correlation with length of maxillary base (PNS-A, $r=0.28)$, a very high statistically significant $(P<0.001)$ very low positive correlation with upper anterior facial height (N-ANS, $r=0.22$ ), a very high statistically significant $(P<0.001)$ very low positive correlation with upper posterior facial height (S-PNS, $r=0.216)$, a statistically insignificant $(P=0.61)$ very low positive correlation with angle of inclination (AOI, $r=0.039$ ).

- Nasal hump showed a statistically insignificant $(P=0.30)$ very low positive correlation with SNA $(r=0.078)$, a statistically insignificant $(P=0.19)$ very low negative correlation with $\mathrm{N}$ perpendicular to $\mathrm{A}(r=-0.098)$, a statistically insignificant $(P=0.99)$ very low positive correlation with length of maxillary base (PNS-A, $r=0.001)$, a statistically insignificant $(P=0.25)$ very low negative correlation with upper anterior facial height (N-ANS, $r=-0.086)$, a statistically insignificant $(P=0.62)$ very low negative correlation with upper posterior facial height (S-PNS, $r$ $=-0.037)$, a statistically insignificant $(P=0.35)$ very low positive correlation with angle of inclination (AOI, $r=0.071$ ).

\section{DISCUSSION}

When nasal length was correlated with sagittal skeletal parameters [Table 2], nasal length depicted an insignificant $(0.26)$ weak positive correlation $(0.084)$ with SNA, and similar findings were also noticed when it is related to $\mathrm{N}$ perpendicular to $\mathrm{A}(r=-0.071$, $P=0.34)$. This is contradicted by the findings of Gulsen et al. ${ }^{[17]}$ who demonstrated a significant weak negative correlation of nasal length with SNA and $\mathrm{N}$ perpendicular to A. Nasal length also showed a significant (0.04) low positive correlation (0.15) with the length of maxillary base. When correlated with vertical skeletal parameters [Table 2], it depicted a significant and high positive correlation with anterior maxillary height, which was in accordance with the findings of Gulsen et al., ${ }^{[17]}$ Karan Nehra and Vineet Sharma. ${ }^{[6]}$ A significant $(P<0.001)$ low positive correlation $(r=0.29)$ was also observed with posterior maxillary height and a significant $(P<0.001)$ low negative correlation $(r=-0.34)$ with angle of inclination, indicating an increased nasal length with downward or clockwise rotation of palatal plane, and decreased nasal length with upward or anti-clockwise rotation of palatal plane. ${ }^{[6]}$

When nasal depth was correlated with sagittal skeletal parameters [Table 2], it showed an insignificant (0.89) weak negative correlation $(-0.10)$ with SNA, and with $\mathrm{N}$ perpendicular to $\mathrm{A}$ too reflected a significant $(P<0.001)$ low positive correlation $(0.28)$ with the length of maxillary base which is in accordance with the findings of Gulsen et al. ${ }^{[17]}$

Nasal depth when correlated with vertical skeletal parameters [Table 2] depicted a significant $(P<0.001)$ and low positive correlation $(r=0.43)$ with anterior maxillary height and a significant $(P<0.001)$ low positive correlation $(r=0.292)$ with posterior maxillary height, which is similar to that of the findings of Gulsen et al. ${ }^{[17]}$ Nasal depth has also shown a significant $(P=0.90)$ 
low negative correlation $(r=-0.01)$ with angle of inclination. Based on these findings, one can expect long nose with an increased nasal prominence (nasal depth) in sagittal and vertical maxillary excess and a short nose with decreased nasal prominence in sagittal and vertical maxillary deficiency. Both nasal length and prominence are highly influenced by anteroposterior length of maxilla than its position.

Naso-labial angle showed no significant correlation with sagittal and vertical maxillary skeletal parameters. When nasolabial angle was correlated with sagittal skeletal parameters [Table 2], it showed an insignificant (0.93) low negative correlation $(-0.006)$ with SNA, an insignificant (0.45) low positive correlation (0.056) with $\mathrm{N}$ perpendicular to $\mathrm{A}$, an insignificant $(0.17)$ low negative correlation $(-0.012)$ with length of maxillary base. With respect to vertical skeletal parameters [Table 2], nasolabial angle showed an insignificant (0.78) low positive correlation (0.021) with anterior maxillary height, with posterior maxillary height and an insignificant $(0.80)$ low negative correlation $(-0.019)$ with Angle of inclination.

Nasal tip angle (N -Prn- $\mathrm{Cm}$ ) studied in relation with sagittal skeletal parameters [Table 2] depicted an insignificant low negative correlation with SNA $(r$ $=-0.019, P=0.80)$, with $\mathrm{N}$ perpendicular to $\mathrm{A}(r=-0.013$, $P=0.86)$ and a significant low negative correlation with length of maxillary base $(r=-0.171, P=0.02)$.

when related with vertical skeletal parameters [Table 2], it showed an insignificant (0.15) low negative correlation $(-0.108)$ with maxillary anterior height and with posterior maxillary height $(P=0.19, r=-0.09)$, which was in agreement with the previous studies. ${ }^{\left[{ }^{[6]}\right.}$ When related with angle of inclination, it showed an insignificant (0.34) low negative correlation $(-0.071)$, which was contrary to the findings of Karan Nehra and Vineet Sharma ${ }^{[6]}$ where they demonstrated a positive correlation of Nasal tip angle.

Columella convexity of the nose studied in relation with sagittal skeletal parameters [Table 2] showed an insignificant low positive correlation with SNA $(r=0.014$, $P=0.85)$ and $\mathrm{N}$ perpendicular to $\mathrm{A}(r=0.046, P=0.54)$. This contradicts the findings reported by Gulsen et al., ${ }^{[17]}$ where they demonstrated a significant $(P<0.05)$ negative correlation $(-0.128)$ with SNA, and insignificant negative correlation $(-0.115)$ with $\mathrm{N}$ perpendicular to $\mathrm{A}$. The significant $(P<0.001)$ low positive correlation $(0.28)$ of columella convexity with the length of maxilla agrees with the findings of Gulsen et al. ${ }^{[17]}$
Columella convexity of the nose when related with vertical skeletal parameters [Table 2] showed a highly significant low positive correlation with both anterior maxillary height $(r=0.22, P<0.001)$ and posterior maxillary height $(r=0.216, P<0.001)$., -with angle of inclination of maxilla it showed an insignificant $(0.61)$ low positive correlation (0.039).

Nasal hump depicted an insignificant and a weak correlation with all of the maxillary skeletal parameters. When related with vertical skeletal parameters [Table 2], it showed an insignificant $(0.30)$ low positive correlation (0.078) with SNA, which is contrary to the findings of Gulsen et al. ${ }^{[17]}$ and an insignificant (0.19) low negative correlation $(-0.098)$ with $\mathrm{N}$ perpendicular to $\mathrm{A}$, which was similar to the findings.

When related with vertical skeletal parameters [Table 2], nasal hump showed an insignificant low negative correlation with anterior $(r=-0.086, P=0.25)$ and posterior maxillary height $(r=-0.037, P=0.62)$. It also showed an insignificant (0.35), low positive correlation (0.071) with angle of inclination.

Gulsen et al. ${ }^{[17]}$ reported a significant positive correlation of nasal length with nasal depth. These findings are supported by Karan Nehra and Vineet Sharma. ${ }^{[6]}$ The findings of the present study agree with their findings, depicting a significant $(P<0.001)$ high positive correlation (0.50) of nasal length with nasal depth [Table 3]. Nasal length also showed a significant (0.011) low positive correlation (0.189) with nasal hump [Table 3]. Thus, based on these findings, one can expect the people with long nose to have

\begin{tabular}{|c|c|c|c|c|c|c|}
\hline & \multicolumn{6}{|c|}{ Correlations } \\
\hline & $\begin{array}{l}\text { N LEN } \\
(\mathrm{mm})\end{array}$ & $\begin{array}{l}\text { N-DEP } \\
(\mathrm{mm})\end{array}$ & $\operatorname{NLA}\left({ }^{\circ}\right)$ & $\begin{array}{c}\text { N-Pr-Cm } \\
\left({ }^{\circ}\right)\end{array}$ & $\begin{array}{c}\text { Cconv } \\
(\mathrm{mm})\end{array}$ & $\begin{array}{l}\text { HUMP } \\
(\mathrm{mm})\end{array}$ \\
\hline \multirow[t]{2}{*}{$\mathrm{N}-\mathrm{LEN}(\mathrm{mm})$} & 1 & $0.509^{* *}$ & 0.034 & $-0.186^{*}$ & 0.003 & $0.189^{*}$ \\
\hline & & 0.000 & 0.646 & 0.012 & 0.967 & 0.011 \\
\hline \multirow[t]{2}{*}{$\mathrm{N}$-DEP $(\mathrm{mm})$} & $0.509^{* *}$ & 1 & $0.152^{*}$ & $-0.477^{\star *}$ & $0.464^{* *}$ & $0.257^{* *}$ \\
\hline & 0.000 & & 0.041 & 0.000 & 0.000 & 0.000 \\
\hline \multirow[t]{2}{*}{$\operatorname{NLA}\left({ }^{\circ}\right)$} & 0.034 & $0.152^{*}$ & 1 & $0.542^{* *}$ & $-0.316^{\star \star}$ & $0.193^{* *}$ \\
\hline & 0.646 & 0.041 & & 0.000 & 0.000 & 0.009 \\
\hline \multirow[t]{2}{*}{$\mathrm{N}-\mathrm{Pr}-\mathrm{Cm}\left({ }^{\circ}\right)$} & $-0.186^{*}$ & $-0.477^{\star *}$ & $0.542^{* *}$ & 1 & $-0.623^{\star *}$ & -0.115 \\
\hline & 0.012 & 0.000 & 0.000 & & 0.000 & 0.126 \\
\hline \multirow[t]{2}{*}{ Cconv $(\mathrm{mm})$} & 0.003 & $0.464^{* *}$ & $-0.316^{* *}$ & $-0.623^{* *}$ & 1 & -0.076 \\
\hline & 0.967 & 0.000 & 0.000 & 0.000 & & 0.308 \\
\hline \multirow[t]{2}{*}{ HUMP (mm) } & $0.189^{*}$ & $0.257^{\star *}$ & $0.193^{* *}$ & -0.115 & -0.076 & 1 \\
\hline & 0.011 & 0.000 & 0.009 & 0.126 & 0.308 & \\
\hline
\end{tabular}

**: Correlation is significant at the 0.01 level (2-tailed), *: Correlation is significant at the 0.05 level (2-tailed), N LEN: N Length, N DEP: N Depth, NLA: Nasolabial angle, N-Pr-Cm: Nasal tip angle, Cconv: Columella convexity, HUMP: Nasal hump 
prominent nasal depth and nasal hump, and those with short nose to have straight nose, without hump and less nasal prominence.

Nasal length showed an insignificant (0.65) low positive correlation (0.03) with nasolabial angle and a significant (.012) low negative correlation $(-0.018)$ with nasal tip angle. With columella convexity, nasal length depicted insignificant (0.97) low positive correlation (0.003) [Table 3], comparative to the findings of previous studies. ${ }^{[17]}$

Gulsenet al..$^{[17]}$ reported a significant $(P<0.01)$ low negative correlation $(-0.209)$ of nasal depth with nasolabial angle. This is contradicted by Karan Nehra and Vineet Sharma, ${ }^{[6]}$ where they reported an insignificant (0.404) low positive correlation (0.061) between nasal depth and nasolabial angle. The findings of the present study were coinciding with the findings of Karan Nehra and VineetSharma, ${ }^{[6]}$ but with variation in significance levels. Nasal depth showed a significant (0.04) low positive correlation (0.15) with nasolabial angle, Columella convexity $(P<0.001$, $r=0.46)$, nasal hump $(P<0.001, r=0.257)$, and with nasal tip angle.

Nasolabial angle showed a significant $(P<0.001)$ high positive correlation (0.54) with nasal tip angle and a significant $(P=<0.001)$ low negative correlation $(r=-0.316)$ with Columella convexity. It also showed a significant $(P=0.009)$ very low positive correlation (0.19) with nasal hump.

Nasal tip angle showed a significant $(P<0.001)$ high negative correlation with $(-0.62)$ with columella convexity, and an insignificant (0.13) low negative correlation $(-0.11)$ with nasal hump. Columella convexity depicted an insignificant $(P=0.31)$ low negative $(-0.076)$ correlation with nasal hump, which is contradicting the findings of Gulsen et al., ${ }^{[17]}$ who suggested a significant $(P<0.001)$ low positive correlation (0.221) between columella convexity and nasal hump.

Ferrario et al ${ }^{[7]}$ studied the growth and development of nose, three dimensionally, and found that volume of nose, external nasal surface, and linear distances were larger in males than in females, with exception of 11-12 years, where females exceeded males with respect to few nasal parameters. Enlow and Hans ${ }^{[18]}$ also reported that the male nose was proportionately larger, more protrusive, and longer than the female nose.
In the present study, a significant influence of sex on nasal parameters was observed [Table $4 \mathrm{a}, 4 \mathrm{~b}$ and Figure 3]. With nasal length and nasal depth being more in males ( $\mathrm{N}$ length $=50.26 \pm 4.18, \mathrm{~N}$ depth $=18.64 \pm 2.56$ ) than in females $(\mathrm{N}$ length $=48.86 \pm 3.45$, $\mathrm{N}$ depth $=16.63 \pm 2.16$ ), and the difference was found to be statistically significant. Fitzgerald et al. ${ }^{[19]}$ who evaluated the nasolabial angle and the relative inclinations of the nose and upper lip in young white adults found no significant gender variation with regard to the nasolabial angle, with the values being $113.55^{\circ} \pm 9.44^{\circ}$ in males and $116.19^{\circ}$ in females, and the difference was found to be statistically insignificant.

Anic Milosevic et al..$^{[20]}$ studied the soft tissue facial profile by means of angular measurements, and found a statistically significant $(P=0.018)$ gender variation of nasolabial angle, with angle being more or wider in women $\left(109.39^{\circ} \pm 7.84^{\circ}\right)$ than in men $\left(105.42^{\circ} \pm 9.52^{\circ}\right)$.

In the present study, no significant (0.338) gender variations were found regarding nasolabial angle, with mean and standard deviation of naso-labial angle being $87.26^{\circ} \pm 13.79^{\circ}$ in males, and $89.38^{\circ} \pm 15.72^{\circ}$ in females.

Nasal tip angle showed a significant $(P<0.001)$ difference between males $\left(73.60^{\circ} \pm 10.24^{\circ}\right)$ and females $\left(80.18^{\circ} \pm 9.44^{\circ}\right)$, with the angle being wider in females than in males. Columella convexity is more in males $(4.31 \pm 1.26)$ than in females $(3.41 \pm 1.13)$. Nasal hump showed no significant (0.97) gender variations, with mean values being $-2.01 \pm 1.76$ in males and $-2.02 \pm 1.62$ in females, which is contradicting the findings of Gulsen et al. ${ }^{[17]}$ where he reported a significant difference in nasal hump, with nasal hump being more in males.

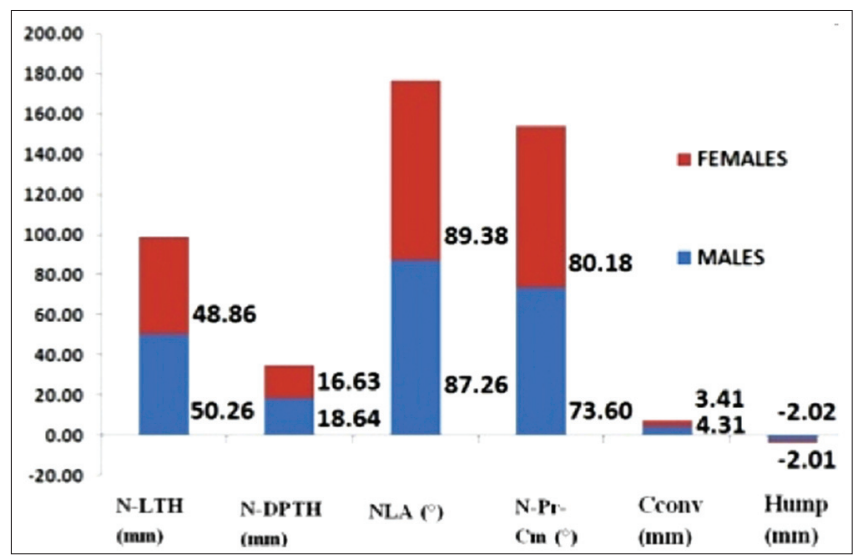

Figure 3: Means of nasal parameters in males and females 


\begin{tabular}{|c|c|c|c|c|c|c|c|c|}
\hline \multicolumn{9}{|c|}{ Descriptive } \\
\hline & \multirow[t]{2}{*}{$N$} & \multirow[t]{2}{*}{ Mean } & \multirow[t]{2}{*}{ SD } & \multirow[t]{2}{*}{ SE } & \multicolumn{2}{|c|}{$95 \%$ confidence interval for mean } & \multirow[t]{2}{*}{ Minimum } & \multirow[t]{2}{*}{ Maximum } \\
\hline & & & & & Lower bound & Upper bound & & \\
\hline \multicolumn{9}{|c|}{ N LEN (mm) } \\
\hline Males & 86 & 50.26 & 4.187 & 0.452 & 49.36 & 51.15 & 40 & 58 \\
\hline Females & 94 & 48.86 & 3.454 & 0.356 & 48.15 & 49.57 & 40 & 56 \\
\hline Total & 180 & 49.53 & 3.874 & 0.289 & 48.96 & 50.10 & 40 & 58 \\
\hline \multicolumn{9}{|c|}{$\operatorname{NDEP}(\mathrm{mm})$} \\
\hline Males & 86 & 18.64 & 2.562 & 0.276 & 18.09 & 19.19 & 10 & 25 \\
\hline Females & 94 & 16.63 & 2.160 & 0.223 & 16.19 & 17.07 & 12 & 23 \\
\hline Total & 180 & 17.59 & 2.561 & 0.191 & 17.21 & 17.97 & 10 & 25 \\
\hline \multicolumn{9}{|l|}{$\operatorname{NLA}\left({ }^{\circ}\right)$} \\
\hline Males & 86 & 87.26 & 13.792 & 1.487 & 84.30 & 90.21 & 47 & 114 \\
\hline Females & 94 & 89.38 & 15.729 & 1.622 & 86.16 & 92.60 & 18 & 124 \\
\hline Total & 180 & 88.37 & 14.832 & 1.106 & 86.19 & 90.55 & 18 & 124 \\
\hline \multicolumn{9}{|l|}{$\mathrm{N}-\operatorname{Pr}-\mathrm{Cm}\left({ }^{\circ}\right)$} \\
\hline Males & 86 & 73.60 & 10.248 & 1.105 & 71.41 & 75.80 & 46 & 98 \\
\hline Females & 94 & 80.18 & 9.441 & 0.974 & 78.25 & 82.11 & 59 & 103 \\
\hline Total & 180 & 77.04 & 10.346 & 0.771 & 75.52 & 78.56 & 46 & 103 \\
\hline \multicolumn{9}{|c|}{ Cconv (mm) } \\
\hline Males & 86 & 4.31 & 1.267 & 0.137 & 4.04 & 4.59 & 2 & 7 \\
\hline Females & 94 & 3.41 & 1.130 & 0.117 & 3.18 & 3.65 & 2 & 7 \\
\hline Total & 180 & 3.84 & 1.276 & 0.095 & 3.66 & 4.03 & 2 & 7 \\
\hline \multicolumn{9}{|c|}{ HUMP (mm) } \\
\hline Males & 86 & -2.01 & 1.766 & 0.190 & -2.39 & -1.63 & -7 & 1 \\
\hline Females & 94 & -2.02 & 1.620 & 0.167 & -2.35 & -1.69 & -6 & 1 \\
\hline Total & 180 & -2.02 & 1.686 & 0.126 & -2.26 & -1.77 & -7 & 1 \\
\hline
\end{tabular}

\section{CONCLUSION}

The following conclusions were obtained from the study:

1. Most of the nasal parameters, when correlated with sagittal maxillary skeletal pattern, showed significant correlation with length of the maxillary base (PNS-A), but none of the parameters showed significant correlation with the position of the maxilla (SNA, $\mathrm{N}$ perpendicular to A). Thus, anteroposterior or sagittal length of maxilla showed greater influence on nasal pattern than its position.

Nasal length, nasal depth, and Columella convexity showed a significant low positive correlation with the length of maxillary base, while nasal hump had a statistically insignificant very low positive correlation. Nasolabial angle showed an insignificant low negative correlation with the length of the maxillary base (PNS-A), whereas nasal tip angle had a statistically significant low negative correlation.

2. When correlated with vertical maxillary skeletal pattern, only three nasal parameters -nasal length, nasal depth, and Columella convexity showed significant positive correlation with both anterior (N-ANS) and posterior (S-PNS) vertical maxillary height, whereas the only nasal parameter that showed significant correlation with angle of inclination (AOI) of palatal plane was nasal length.

3. A significant influence of gender variation was seen on all the nasal parameters, except nasolabial angle (NLA) and nasal hump. Nasal length, nasal depth, columella convexity, and nasal hump were more in males than in females, while nasolabial angle (NLA) and nasal tip angle were wider in females than in males.

The present study was conducted on south Indian origin individuals, and thus the results cannot be generalized, as the nasal pattern differs from individual to individual and form human race to race. Thus, the study needs to be further compared and correlated with future studies and larger samples to establish any standardized norms. 
Prasad, et al.: Nasal morphology in predicting maxillary skeletal discrepancies

\begin{tabular}{|c|c|c|c|c|c|}
\hline & \multicolumn{5}{|c|}{ ANOVA } \\
\hline & $\begin{array}{l}\text { Sum of } \\
\text { squares }\end{array}$ & df & $\begin{array}{l}\text { Mean } \\
\text { square }\end{array}$ & $F$ & Sig. \\
\hline \multicolumn{6}{|l|}{ N LEN (mm) } \\
\hline Between groups & 87.287 & 1 & 87.287 & 5.977 & 0.015 \\
\hline Within groups & 2599.574 & 178 & 14.604 & & \\
\hline Total & 2686.861 & 179 & & & \\
\hline \multicolumn{6}{|l|}{$\operatorname{NDEP}(\mathrm{mm})$} \\
\hline Between groups & 181.784 & 1 & 181.784 & 32.625 & 0.000 \\
\hline Within groups & 991.794 & 178 & 5.572 & & \\
\hline Total & 1173.578 & 179 & & & \\
\hline \multicolumn{6}{|l|}{$\mathrm{NLA}\left({ }^{\circ}\right)$} \\
\hline Between groups & 203.215 & 1 & 203.215 & 0.923 & 0.338 \\
\hline Within groups & 39176.585 & 178 & 220.093 & & \\
\hline Total & 39379.800 & 179 & & & \\
\hline \multicolumn{6}{|l|}{$\mathrm{N}-\operatorname{Pr}-\mathrm{Cm}\left({ }^{\circ}\right)$} \\
\hline Between groups & 1942.244 & 1 & 1942.244 & 20.081 & 0.000 \\
\hline Within groups & 17216.484 & 178 & 96.722 & & \\
\hline Total & 19158.728 & 179 & & & \\
\hline \multicolumn{6}{|l|}{ Cconv (mm) } \\
\hline Between groups & 36.302 & 1 & 36.302 & 25.306 & 0.000 \\
\hline Within groups & 255.342 & 178 & 1.435 & & \\
\hline Total & 291.644 & 179 & & & \\
\hline \multicolumn{6}{|l|}{ HUMP (mm) } \\
\hline Between groups & 0.004 & 1 & 0.004 & 0.001 & 0.970 \\
\hline Within groups & 508.946 & 178 & 2.859 & & \\
\hline Total & 508.950 & 179 & & & \\
\hline
\end{tabular}

\section{REFERENCES}

1. Subtelny JD. The soft tissue profile, growth and treatment changes. Angle Orthod 1961;31:105-122.

2. Milton N. A quantitative method for the evaluation of the soft-tissue facial profile. Am J Orthod 1959; 45:738-51.

3. Burstone CJ. Integumental contour and extension patterns. Angle Orthod 1959;29:93-104.

4. Genecov JS, Sinclair PM, Dechow PC. Development of the nose and soft tissue profile. Angle Orthod 1990;60:191-8.
5. Meng HP, Goorhuis J, Kapila S, Nanda RS. Growth changes in the nasal profile from 7 to 18 years of age. Am J Orthod Dento facial Orthop 1988;94:317-26.

6. Nehra K, Sharma V. Nasal morphology as an indicator of vertical maxillary skeletal pattern. J Orthod 2009; 36:160-6.

7. Ferrario VF, Sforza C, Poggio CE, Schmitz JH. Three-dimensional study of growth and development of the nose. Cleft Palate Cranio fac J 1997; 34:309-17.

8. Wisth PJ. Nose morphology in individuals with Angle Class I, Class II, or Class III occlusions. Acta Odontol Scand 1975; 33:53-7.

9. Clements BS. Nasal imbalance and the orthodontic patient. Am J Orthod 1969; 55:477-98.

10. Gungor AY, Turkkahraman H. Effects of airway problems on maxillary growth: A review. Eur J Dent 2009; 3:250-4.

11. Babula WJ Jr, Smiley GR, Dixon AD. The role of the cartilaginous nasal septum in midfacial growth. Am J Orthod 1970; 58:250-63.

12. Uzuner FD, Darendeliler N. Dentoalveolar surgery techniques combined with orthodontic treatment: A literature review. Eur J Dent 2013; 7:257-65.

13. Thilander B. Basic mechanisms in craniofacial growth. Acta Odontol Scand 1995; 53:144-51.

14. Burke PH, Hughes-Lawson CA. Stereo photogrammetric study of growth and development of the nose. Am J Orthod Dento facial Orthop 1989; 96:144-51.

15. Jacobson A, Jacobson RL. Radiographic Cephalometry: From Basics to Video-imaging. $2^{\text {nd }}$ ed. Chicago: Quintessence Publishing CoInc; 2006.

16. Rakosi T. An Atlas and Manual of Cephalometric Radiography. $2^{\text {nd }} e d$. New York: Wolfe Medical Publications Ltd; 1982.

17. Gulsen A, Okay C, Aslan BI, Uner O, Yavuzer R. The relationship between craniofacial structures and the nose in Anatolian Turkish adults: A cephalometric evaluation. Am J Orthod Dentofacial Orthop 2006; 130:131.15-5.

18. Enlow DH, Hans MG. Essentials of Facial Growth. $1^{\text {st }}$ ed. Philadelphia, PA: WB Saunders Company; 1996.

19. Fitzgerald JP, Nanda RS, Currier GF. An evaluation of the nasolabial angle and the relative inclinations of the nose and upper lip. Am J Orthod Dento facial Orthop 1992; 102:328-34.

20. Anić-Milosević S, Lapter-Varga M, Slaj M. Analysis of the soft tissue facial profile by means of angular measurements. Eur J Orthod 2008; 30:135-40.

\begin{tabular}{|c|c|}
\hline \multicolumn{2}{|c|}{ Access this article online } \\
\hline $\begin{array}{l}\text { Quick Response Code: } \\
\end{array}$ & $\begin{array}{l}\text { Website: } \\
\text { www.eurjdent.com }\end{array}$ \\
\hline $17+2$ & $\begin{array}{l}\text { Source of Support: Nil. } \\
\text { Conflict of Interest: None declared }\end{array}$ \\
\hline
\end{tabular}

